\title{
A Semantic Argument for Complex Predicates ${ }^{*}$
}

\author{
Jack Hoeksema \\ University of Groningen
}

\section{The Issue: The proper treatment of predicative structures}

The problem of complex predicate expressions arises in a number of areas. One of these is the area of predicative constructions such as consider yourself lucky and resultatives, like paint oneself into a corner. Another is the area of auxiliaries and semi-auxiliaries, which in some languages cluster with the main verb, for instance in Dutch or German. I will present a semantic account of complex predicates which has consequences for both types of cases.

Predicative constructions of the consider-type have been the focus of a prolonged debate. The main possibilities for analyzing these expressions are

I. complex-predicate analysis: consider lucky + yourself

II. small-clause analysis: consider + [yourself lucky]

III. ternary analysis: consider + yourself + lucky

IV. combinations of the above (e.g. small clause underlying, complex predicate at surface structure or logical form)

My approach to the constructions at hand is an eclectic one. For certain constructions, where standard constituency tests are compatible with a small-clause analysis, I assume small clauses. This is the case, for instance, for absolute constructions, as in (1):

(1) His army defeated and his hopes shattered, Napoleon embarked for Saint Helena.

When the usual constituency tests do not point towards small clauses, I assume a complex-predicate analysis. A case in point is the argument structure of the verb consider. Here we see that fronting or clefting the putative small clause is not possible:

(2) a. Alfred considered Agnes eligible.

b. *Agnes eligible was considered by Alfred

c. *Agnes eligible, Alfred considered.

d. *It was Agnes eligible, that Alfred considered.

I will hence assume that consider does not have a small-clause complement.

It has been argued by small-clause theorists (e.g. Stowell 1983) that the phantomlike character of small clauses is due to independent properties of the grammar, primarily having to do with case assignment, which rule out fronting, extraposition or clefting of entire small clauses. ${ }^{1}$ However, this suggestion does not seem correct 
in light of the following observation. Pollard and Sag, in their forthcoming book on Head-Driven Phrase Structure Grammar, point out an interesting difference between verbs like consider on the one hand and verbs such as want or fear on the other hand. The complements of the latter verbs may show small-clause properties under clefting and fronting: ${ }^{2}$

(3) a. We feared Noriega in power.

b. What we feared most was Noriega in power.

c. Noriega in power was what we feared most.

d. It was Noriega in power that we feared most.

e. Noriega in power, we need not fear.

A case-driven small-clause theory in the manner of Stowell would not predict the acceptability of the data in (3b-e). These observations lead to a new question: Does the difference between consider-type verbs and want-type verbs have a semantic correlate? Before answering this question, I briefly turn to some issues involving monotonicity patterns. ${ }^{3}$

\section{Functions, arguments \& monotonicity}

Monotonicity patterns concern the inferential properties of functions and arguments. For arguments, there are three basic cases to be distinguished, dependent on the semantic properties of the function:

\section{A: Dictum de Omni (valid for Mon $\uparrow$ functions F)}

$\mathrm{F}(\mathrm{A})$

$\mathrm{A} \leq \mathrm{B}$

$\mathrm{F}(\mathrm{B})$
Ex: All philosophers (are human)

human $\leq$ mortal

All philosophers (are mortal)

\section{B: Dictum de Nulli (valid for Mon $\downarrow$ functions F)}

$\mathrm{F}(\mathrm{A})$

$\mathrm{B} \leq \mathrm{A}$

$\mathrm{F}(\mathrm{B})$
Ex.: No philosophers (are immortals) angels $\leq$ immortals

No philosophers (are angels)

\section{C: None of the above}

When $\mathrm{F}$ is nonmonotone, neither replacement by entailing nor replacement by entailed elements is valid. Ex.: Some but not all philosophers (are Germans) together with Prussians $\leq$ Germans $\leq$ Europeans neither implies 
that some but not all philosophers are Prussians nor that some but not all philosophers are European.

For functions, we can define " $\leq "$ in a pointwise fashion:

$$
F \leq F^{\prime} \text { iff } F(A) \leq F^{\prime}(A) \text { for any } A \text { in the domain of } F \text { and } F^{\prime}
$$

From this definition, it follows that the Dictum de Omni, which takes the form in (6) in this case, is always valid, at least within the confines of the functionargument combination:

$$
\begin{aligned}
& F(A) \\
& F \leq F \\
& \hdashline F^{\prime}(A)
\end{aligned}
$$

This gives us a test to distinguish functions from arguments: replacement of an argument is sensitive to the monotonicity properties of the function, but replacement of a function is not dependent on the monotonicity properties of its argument.

As has been noted by Van Benthem (1987), Keenan (1987) and others, this implies that in a subject-predicate combination, the main functor is the subject, not the predicate. This is in line with Montague's PTQ, much of generalized quantifier theory and Keenan's Semantic Case Theory, but goes against the treatment in Keenan and Faltz (1985), for example. We clearly see the effect of the subject in the examples in (4) above. Within a transitive verb phrase, the direct object acts as the main functor, and the transitive verb as its argument (Sommers 1982, Keenan 1987). Witness the patterns in (7), where we are tacitly assuming that strangling entails killing:
a. strangle the MP
$\Rightarrow \quad$ kill the MP
b. strangle no MP
$\Leftarrow \quad$ kill no MP
c. strangle each MP
$\Rightarrow \quad$ kill each MP
d. strangle neither MP
$\Leftarrow \quad$ kill neither MP
e. strangle some but not all MPs
$\Leftarrow / \Rightarrow$ kill some but not all MPs

We see that the replacement of strangle by kill or vice versa depends on the properties of the direct object. This behavior is typical for most transitive verbs, and universal for all extensional transitives. It it less clear, at first sight, whether it also applies to opaque transitive verbs. Recall Montague's treatment of intensionality in PTQ, which crucially assumed the object to be the argument of the intensional verb. Now one of the unsatisfactory aspects of Montague's treatment is its failure to deal with certain valid inferences in opaque contexts. For instance, the inference in (8) seems intuitively valid: 
Eddy wants a Visa card

Visa card $<$ credit card

Eddy wants a credit card

In intensional domains, such substitutions are not allowed, and clearly, we would not want them in say, the complement of a propositional-attitude verb. If Eddy believes that a Visa card will save his life, he need not be held to believe that a credit card will save his life.

Another type of inference not validated on Montague's account involves substitutions of verbs by more or less specific ones. Consider for instance the inference in (9):

$$
\begin{aligned}
& \text { Eddy wants fewer than three things } \\
& \text { crave for } \leq \text { want }
\end{aligned}
$$

Eddy craves for fewer than three things

This is the kind of monotonicity inference that we have seen in (7). If we were to treat the object as the main functor, it would follow without further stipulation. What then; about the intensionality of the verb want? My suggestion would be to treat the basic domain of quantification as a more intensional set of items than is usually envisaged, and to allow nonexisting objects to be included in it. Exist will become a regular (nontrivial) predicate, and special meaning postulates may tell us when existence is implicated. For instance, kissing something may entail its existence, whereas wanting something does not. This has the pleasing consequence that we can view want and kiss as being truly on a par in terms of their semantic type, and only different in their existential entailment properties.

By treating the object as the main functor in a verb-object combination, we predict that negative polarity items, such as anything, cannot be triggered by a transitive verb. Given that the object is the main functor, it will be subject to the Dictum de Omni, and not to the Dictum de Nullo, which operates in domain of downward-entailing functors. The correctness of the prediction is not entirely clear. It has been argued to be correct by E. Hoekstra (cf. Hoekstra 1991) and L. Progovac (cf. Progovac 1994), but counterexamples have cropped up in the literature (Ladusaw 1980, Zwarts 1986). In (10), a number of relevant examples involving such negative verbs as lack, avoid, deny are given, all taken from the Oxford English Dictionary on CD-ROM:

(10) a. Though he decidedly comes to praise Caesar, not to bury him, he avoids any excessive lues Boswelliana. (s.v. lues Boswelliana)

b. In order to avoid any possible ambiguity, it is the Institution's policy to encourage the use of the terms 'flammable' and 'nonflammable' rather than 'inflammable' and 'non-inflammable'. (s.v. flammable)

c. Count Wolf von Westarp, co-founder of the band of neo-Nazis, has 
indignantly denied any Red ties. (s.v. red)

d. The eighty-six men assigned to the 'dysfunctional' group also lacked any quasi-marital partnership and often expressed regret about their homosexuality, but they were sexually more active and promiscuous. (s.v. quasi-)

The analysis of these verbs is more complex than I can deal with here. As Victor Sanchez (p.c.) pointed out to me, if we treat such verbs simply as downward-entailing functions, we may explain the grammaticality of the above examples, but we wrongly predict that the inference in (11) is valid:

(11) The count denied everything said against him thing said against him $\leq$ thing

The count denied everything

The prediction would follow from the fact that both deny and every are downward-entailing, and thus, in combination, create an upward-entailing environment. Another possibility is that the examples in (10) involve free-choice any. This seems equally wrong, since it does not explain why replacing for example denied by admitted in (10c) yields a less acceptable sentence.

A third option is that the verbs in (10) are downward-entailing functions of a special kind, perhaps taking arguments of type $<e, t>$. This would disallow genuine quantifiers as their arguments, but permit indefinite arguments, if we assume a type-shifting account à la Partee (1987). For a detailed and wellmotivated proposal along these lines, I refer the reader to Zimmermann (19921993).

\section{Monotonicity and complex sentences}

Armed with our preliminary findings regarding subjects and objects in simple clausal structures, let us now move on to complex sentences. As the examples in (12) show, the matrix verb is never in a position where it is under the semantic influence of the subject of the embedded clause. Its substitutional properties are independent of whether the embedded subject is downward, upward, or nonmonotone: 
(12) Mon $\downarrow$ embedded subject

Eddy yelled that at most two boys had to leave the field yell $\leq$ say

Eddy said that at most two boys had to leave the field

\section{Mon $\uparrow$ embedded subject}

Peggy hoped ardently that all would leave hope ardently $\leq$ hope

Peggy hoped that all would leave

Nonmonotone embedded subject

Peggy alleged that some but not all had slandered her allege $\leq$ claim

Peggy claimed that some but not all had slandered her

The examples in (12) involve that-clauses, but adjunct-clauses and for-to clauses work similarly. Next, let us consider the case of complex predicative constructions. In (13), we see some valid inferences involving the resultative construction:

(13) Eddy waltzed his soles thin waltz $\leq$ dance

Eddy danced his soles thin

Eddy danced none of his soles thin waltz $\leq$ dance

Eddy waltzed none of his soles thin

In (14), the consider-construction is exemplified. For the sake of the argument, I will assume that to call someone attractive entails considering that person attractive, but not vice versa. 
(14) Eddy called Peggy attractive

call $\leq$ consider

Eddy considered Peggy attractive

Eddy considered nobody attractive

call $\leq$ consider

Eddy called nobody attractive

From (13) and (14), we may infer that both the resultative and the consider/call-construction behave like transitive structures, and not like complex sentences. Under a small clause analysis, we would predict the quantifiers in subject position to have no influence on the matrix verb. ${ }^{4}$ Under a complexpredicate analysis, on the other hand, the prediction would be that any part of the complex-verb is sensitive to the monotonicity of the object, and that substitutional possibilities are dictated by the status of the object. This is precisely what we see in these examples.

What about constructions with want or fear? Judgments here are rather subtle. Consider the inferences in (15):

(15) A: Eddy feared Noriega dead

fear $\leq$ expect

Eddy expected Noriega dead

B: $\quad$ Eddy expected at most two people dead

fear $\leq$ expect

Eddy feared at most two people dead

C: $\quad$ Eddy feared at most two people dead

fear $\leq$ expect

Eddy expected at most two people dead

Inference A is easily verified as valid. Concerning B and C there is less clarity. I assume that both patterns are valid, because the predicates allow two readings in each case. On the wide scope reading, there are at most two people who Eddy fears or expects dead. On that reading, the inference in B is valid. On the narrow scope reading, Eddy fears that there are at most two people dead, perhaps because he had been hoping for more casualties. Under that reading, the inference in $\mathrm{C}$ is valid. Similar examples are given in (16) for want and like: ${ }^{5}$ 
(16) A: Eddy wants Noriega off his ship want $\leq$ like

Eddy likes Noriega off his ship

B: Eddy likes nobody off his ship want $\leq$ like

Eddy wants nobody off his ship

C: $\quad$ Eddy wants nobody off his ship want $\leq$ like

Eddy likes nobody off his ship

The difference between want and consider is also clear in examples such as (17):

a. Peggy considers at most three dances sinful.

b. Peggy wants at most three dances banned.

In (17b), there is a clear ambiguity. Either Peggy wants to reduce the number of permitted danced by at most three, or else there are at most three dances that she wants banned. In the former case she may not have any opinion about any individual dances, in the latter case she must have such opinions. In (17a), there is no corresponding ambiguity. There is only a wide-scope reading, the one corresponding to (18a), while there is no reading corresponding to (18b):

(18) a. Peggy thinks of at most three dances that they are sinful.

b. Peggy thinks that at most three dances are sinful.

This suggest that want-type verbs support a systematic ambiguity between a smallclause reading, which goes hand in hand with narrow scope for quantifiers in subject position, and a complex-predicate reading, which corresponds to a widescope reading. ${ }^{6}$

The double analysis can be motivated independently. We have already seen syntactic evidence from standard constituency tests to show that want-type verbs may have small-clause arguments. There is syntactic evidence for a complexpredicate analysis as well. For fear and rather more marginally want, there is the possibility of a passive, a possibility most easily accommodated on a complexpredicate theory (as Bach 1979, 1980) already pointed out:

(19) a. Noriega was feared captured.

b. Most passengers are feared dead.

Another argument for complex predicates may be gained from the possibility of pro-forms for the complex predicate in the so-called pseudo-gapping 
construction (cf. Hoeksema 1991) and in antecedent-contained deletion (when analysed as in Jacobson 1992), cf. the examples in (20a-c) and (20d-f) respectively:

(20) a. More people wanted Noriega dead than did Saddam Hussein.

b. Eddy wanted more women on his ship than he did men.

c. The CIA feared Noriega in power like they did Idi Amin.

d. Noriega did not want anybody off his ship who the FBI did.

e. Eddy feared dead none of the people that we did.

f. Peggy wants everything out of this of fice that Eddy doesn't.

\section{Complex Predicates and Negative Polarity Items}

The complex predicate analysis can be further distinguished from the smallclause analysis in the predictions it makes concerning negative-polarity items. Consider for example the sentences in (21):

(21) a. The FBI need fear nobody.

b. You need worry about nothing.

c. One need say very little.

In these examples, the modal verb need, a negative-polarity item, is triggered by the negative complements to the main verb. This can be shown if we compare the examples in (21) with their ungrammatical counterparts in (22):

(22) a. *The FBI need fear everybody.

b. *You need worry about lots of things.

c. $\quad *$ One need say rather a lot.

If complex predicates act like regular transitive verbs with respect to the triggering of need, one would expect the acceptability of the examples in (23):

(23) a. You need consider none of this necessary.

b. Eddy need force nobody off his ship.

c. Peggy need pronounce nobody man and wife.

Similar examples can be given for Dutch, with the modal polarity-sensitive auxiliary verb hoeven, and for German, with the modal polarity item brauchen:

(24) Eddy hoeft niemand aardig te vinden (Dutch)

Eddy need nobody nice to find

"Eddy need find nobody nice" 
(25) Eddy braucht keinen nett zu finden (German)

Eddy need nobody nice to find

"Eddy need find nobody nice"

Subjects of embedded clauses, on the other hand, do not license the occurrence of need in the matrix clause. This can be seen in (26):

(26) a. *You need think that nothing matters.

b. $\quad$ *Eddy need make sure that nobody leaves his ship.

c. *Peggy need state that nobody is man and wife.

d. $\quad$ *Peggy need fear for nobody to dislike her"

For want and fear, we expect that need can be licensed, if indeed there is an optional complex-predicate reading, as I have argued. Relevant examples are given in (27):

(27) a. You need fear nobody dead or wounded.

b. Eddy need want nobody off his ship.

I take these to be grammatical on a wide-scope reading.

The examples in (21), (23) and (27) are not easy to analyse. Can we maintain that an auxiliary verb occurs within the scope of the direct object? If we assume a structure as in (28) for (21a), we can only get the auxiliary within the scope of the object, if we assume a function-argument structure as in (29):

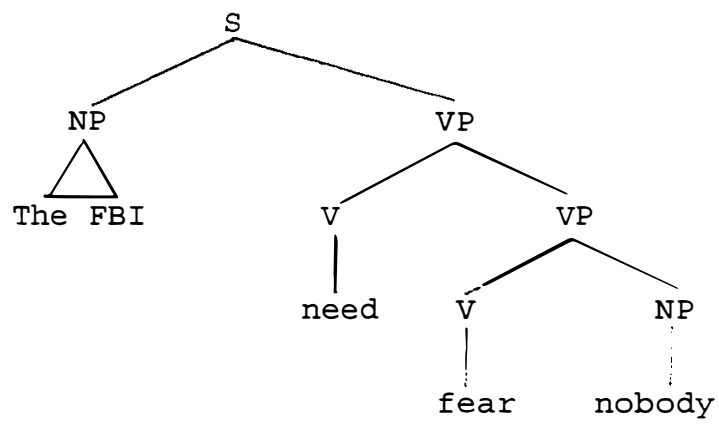

(29)

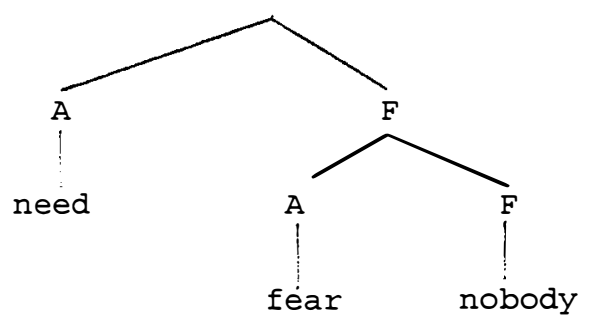

However, this is not an attractive solution. For negative auxiliaries, such as cannot 
or won't, it is clearly necessary to view the VP as the argument of the auxiliary, in order to understand their monotonicity properties and polarity-licensing behavior. An alternative is to view the auxiliary as a possible sister of the main verb, as in (30):

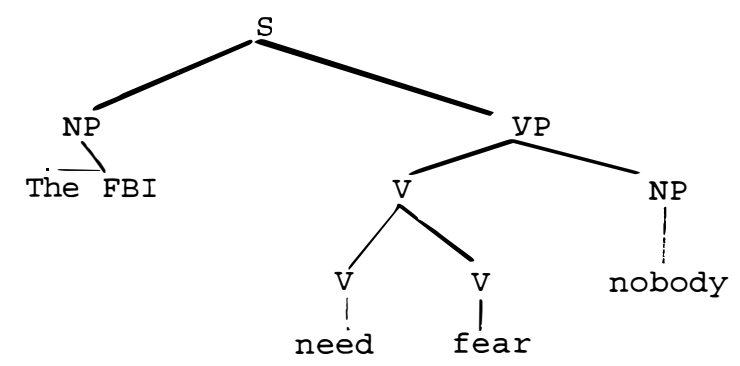

Given that there is also considerable evidence for the structure in (28) (cf. Gazdar, Pullum and Sag 1982), I take it that (30) is an optional variant of (28). The structure in (28) is needed to analyse example (31):

The FBI need not fear anybody.

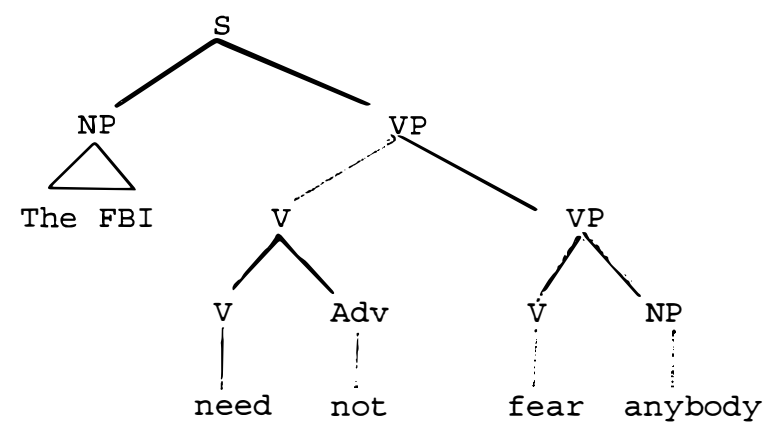

By treating not as the main operator in this structure, we can explain why it may trigger both need and anybody. By composing with need, it creates a downwardentailing function need not, which takes as its argument the VP fear anybody.

For complex predicates, a more involved analysis has to be considered, in which the complex predicate is split up in two parts, to allow the direct object between the verbal and the nonverbal elements. This can be done in a number of ways, for instance by using wrapping à la Bach (1979), or by liberation à la Zwicky (1986), and also Hoeksema (1991).

Before I present my conclusions, I should point out that need is not the only negative-polarity item that small-clause theorists have to worry about. There are other cases were elements outside the alleged small clause domain are triggered by the small clause subject. Consider for instance example (33):

(33) Peggy considered [none of Eddy's behavior acceptable] ever again. 
It is clear that ever again may be construed as modifiers of the main verb. That is to say, (33) is equivalent to (34):

Peggy never again considered any of Eddy's behavior acceptable.

Since ever is probably best viewed as a VP-adjunct, it is not entirely clear how it could be triggered by material within the VP. Perhaps it is optionally treated as a complement to the verb, along the lines of McConnell-Ginet (1982). This could help explain why ever must appear postverbally in (33), in a complement position, but not preverbally, as in (35):

*Peggy ever again considered none of Eddy's behavior acceptable.

The usual explanation for the ungrammaticality of sentences such as (35) is that they constitute a violation of the leftness condition on polarity licensing (Jackendoff 1972, Ladusaw 1979). However, the leftness condition would also rule out our examples with need, so that any appeal to this condition would be most unfortunate.

\section{Summary and conclusions}

So-called small-clause subjects may sometimes behave semantically like direct objects in terms of scope and licensing behavior. In such cases, a complexpredicate analysis is best suited to deal with the structures at hand. This was argued to be the case both for structures headed by members of the consider-class of verbs and for resultative constructions. On the other hand, structures headed by such verbs as want or fear may behave in a systematically ambiguous fashion. I have proposed that both a complex-predicate and a small-clause analysis may be correct for these latter structures. The possibility of systematic ambiguity is not usually welcomed in the generative tradition. In categorial grammar, it is more widely accepted, but often in an across-the-board fashion which does not distinguish between individual verbs. However, I see no way around constructionspecific systematic ambiguity.

I have refrained from dealing with the raising-to-object construction here. However, as Borkin $(1974=1984)$ pointed out, the scope-ambiguity noted here for want-type structures also exists for raising-to-object constructions:

(36) Roger Mudd cheerfully reported C Troop alone to be crossing the border. (Borkin 1974 =1984: 31)

The narrow scope reading, which is most prominent in (36), does not exist for the somewhat marginal sentence in (37), according to Borkin's informants:

(37) Roger Mudd reported C Troop alone as crossing the border. (Borkin 1974 = 1984: 32) 
If a wide-scope reading is more difficult to get for (36) than it is for (37), we predict that (38b) is more easily recognized as acceptable than (38a):

(38) a. Roger Mudd need report C Troop alone to be crossing the border.

b. Roger Mudd need report C Troop alone as crossing the border.

This evidence suggests that the report+to construction is ambiguous, while the report+as construction is an unambiguous complex predicate. What is problematic about these data is that constituency tests such as fronting or clefting do not support clausal constituency for either construction.

\section{Notes}

* I thank the audiences at SALT and the University of Califomia at Santa Cruz (where an earlier version of this paper was presented) for their valuable comments and criticism. The research reported here was supported by a grant from the Pionier program of the Dutch Organization for Research (NWO).

1 The crucial assumption here (cf. Stowell 1981) is that accusative case assignment requires adjacency of the noun phrase or its trace to the assigning verb or preposition. When a small clause is moved, or occurs in a cleft construction, its subject is not adjacent to the verb which should assign it accusative case, nor does it bind a trace with meets the adjacency requirement.

2 Similar behavior can be noted for Dutch willen "want, wish":

(i) a. Het volk wil Alexander op de troon the people wants Alexander on the throne

b. Wat het volk wil is Alexander op de troon what the people wants is Alexander on the throne

c. Alexander op de troon wil het volk Alexander on the throne wants the people

There is even evidence for peaceful coexistence of small-clause and complexpredicate structure in one sentence:

(ii) Het volk heeft het liefst Alexander op de troon

the people has the dearest Alexander on the throne

"The people prefers Alexander on the throne"

In (ii), the combination het liefst hebben acts as a complex predicate, with a smallclause complement Alexander op de troon which can be fronted or treated as the focus of a cleft: 
(iii) a. Wat het volk het liefst heeft is Alexander op de troon what the people the dearest have is Alexander on the throne "What the people prefer is Alexander on the throne"

b. Alexander op de troon heeft het volk het liefst. Alexander on the throne has the people the dearest "Alexander on the throne, the people prefer"

However, the same constituency tests do not here allow for the possibility of a small clause within a small clause, a possibility often presumed possible in the literature. Cf. the crashingly bad examples in (iv):

(iv) a. *Wat het volk heeft is Alexander op de troon het liefst. what the people have is Alexander on the throne the dearest

b. *Alexander op de troon het liefst heeft het volk.

Alexander on the throne the dearest has the people

3 For related discussion, see also Dowty, this volume.

4 At least if the small clause subject is still within the small-clause domain at surface structure or whatever level determines scope assignment. My argument against small clauses does not extend to theories which postulate a derived position for small-clause subjects outside the small clause. However, if a small-clause subject is not inside the small clause at surface structure, the evidence for an underlying small clause position will turn out to be difficult to come by.

5 A naturally-occurring example of fear with a predicative complement can be found in Shakespeare's Henry VI, part 3:

(i) The Theefe doth feare each bush an Officer.

Presumably, the intended reading has wide scope for each bush: each bush is feated as a potential officer. The narrow scope reading, where there is a fear lest each bush might be an officer, involves what appear to be contradictory beliefs.

6 Williams (1983: 294) also mentions the possibility of a narrow scope reading for quantifiers following want. His example is

I want someone there.

(= I want (someone there))

Williams mentions the possibility of a small-clause analysis for this case, but thinks it is not necessary to adopt it, given that the narrow-scope reading could be due to the generally intensional character of the verb want. However, the observations by Pollard and Sag make a small-clause analysis more credible. 


\section{References}

Bach, Emmon (1979) "Control in Montague Grammar". Linguistic Inquiry 10-4, 515-531.

Bach, Emmon (1980) "In Defense of Passive". Linguistics and Philosophy 3, 297341.

Benthem, Johan van (1987) review of "Boolean Semantics for Natural Language" by Edward L. Keenan and Leonard M. Faltz, Language 62-4, 908-914.

Borkin, Ann (1974) Problems in form and function. Doctoral dissertation, University of Michigan, published in 1984 by Ablex, Norwood.

Dowty, David (1994) "The role of negative polarity and negative concord in natural language reasoning", this volume.

Gazdar, Gerald, Geoffrey K. Pullum and Ivan A. Sag (1982) "Auxiliaries and Related Phenomena in a Restrictive Theory of Grammar", Language 58-3, 591-638.

Hoeksema, Jack (1991) "Complex Predicates and Liberation in Dutch and English", Linguistics and Philosophy 14-4, 661-710.

Hoekstra, Eric (1991) Licensing Cnditions on Phrase Structure. Doctoral dissertation, University of Groningen.

Jackendoff, Ray S. (1972) Semantic Interpretation in Generative Grammar, MITPress, Cambridge.

Jacobson, Pauline (1992) " Antecedent Contained Deletion in a Variable-Free Semantics", in: C. Barker and D. Dowty, eds., SALT II. Proceedings of the second conference on semantics and linguistic theory, Ohio State University Working Papers in Linguistics 40, Columbus, 193-213.

Keenan, Edward L. (1987) "Semantic Case Theory", in: J. Groenendijk and M. Stokhof, Proceedings of the Sixth Amsterdam Colloquium, Mathematisch Centrum, Amsterdam.

Keenan, Edward L. and Leonard M. Faltz (1985) Boolean Semantics for Natural Language, Reidel, Dordrecht.

Ladusaw, William A. (1979) Polarity Sensitivity as Inherent Scope Relations, doctoral dissertation, University of Texas at Austin.

Ladusaw, William A. (1980) "On the notion affective in the analysis of negative polarity items". Journal of Linguistic Research 1-1, 1-16.

McConnell-Ginet, Sally (1982) "Adverbs and Logical Form", Language 58, 144-184.

Partee, Barbara H. (1987) "Noun Phrase Interpretation and Type Shifting Principles". In: Jeroen Groenendijk, Dick de Jongh and Martin Stokhof, eds., Studies in Discourse Representation Theory and the Theory of Generalized Quantifiers, Foris, Dordrecht, 115-143.

Pollard, Carl and Ivan A. Sag, to appear, Head-Driven Phrase Structure Grammar.

Progovac, Ljiljana (1994) Negative and positive polarity: a binding approach. Cambridge University Press, Cambridge.

Sommers, Fred (1982) The Logic of Natural Language. Clarendon Press, Oxford. Stowell, Tim (1981) Origins of Phrase Structure, doctoral dissertation, MIT. 
Stowell, Tim (1983) "Subjects across Categories", The Linguistic Review, 2-3, 285-312.

Williams, Edwin S. (1983) "Against Small Clauses", Linguistic Inquiry 14-2, 287-308.

Zimmermann, T. Ede (1992-1993) "On the proper treatment of opacity in certain verbs", in: Natural Language Semantics, vol. 1, no. 2, 149-179.

Zwarts, Frans (1986) "Polariteit: De reikwijdte van een lexicale eigenschap", C. Hoppenbrouwers, I. Schuurman, R. van Zonneveld and F. Zwarts, eds., Syntaxis en Lexicon, Foris, Dordrecht.

Zwicky, Amold (1986) "Concatenation and Liberation", CLS 22, pt 1, 65-74. 